\title{
Hypolipidemic activity of Kadukkai Chooranam (Terminalia chebula) in Triton WR - 1339 induced hyperlipidemic rats.
}

\author{
Priya F*', Velpandian V, Ayyasamy S, Pitchiahkumar M \\ Post Graduate Department of Gunapadam (Pharmacology), Government Siddha Medical College, \\ Arumbakkam, Chennai -106, Tamilnadu, India.
}

\begin{abstract}
Aim: To validate the hypolipidemic efficacy of Kadukkai Choornam (Terminalia chebula) in Triton WR - 1339 induced hyperlipidemic rats. Study design: Experimental Study Place and Duration of the Study: Post Graduate Department of Pharmacology, Government Siddha Medical College, Arumbakkam, Chennai 106, Tamilnadu, India, between August 2012 to December 2012.Methodology: Fresh fruits of Terminalia chebula (Kadukkai) were collected and identified by the botanist. After authentication, pericarp was separated from the fruit and was used for the preparation of Kadukkai Choornam (powder form of pericarp of Terminalia chebula) as per the classical Siddha literature. This powder form was tested against Triton induced hyperlipidemic rats. The experimental procedure was carried out for 7 days. Rats are provided normal diet and water ad libitum. Two doses of $250 \mathrm{mg} / \mathrm{kg}$ and $500 \mathrm{mg} / \mathrm{kg}$ were selected for experimental study. Statistical analysis of lipid profile, liver lipid profile, body weight, organ weight and atherogenic index were done and compared with triton control group, standard group and normal control group. Results: There was no significant increase in the weight of drug treated groups and standard group rats. Kadukkai chooranam at the dose of $250 \mathrm{mg}$ and $500 \mathrm{mg} / \mathrm{kg}$ significantly reduced the serum total cholesterol, triglycerides, LDL and VLDL and increases the high density lipoprotein when compared to the triton control group. This observation indicated that Kadukkai Choornam has hypolipidemic effect on both doses. Higher dose reduced the lipid profile more significantly than lower dose level which indicated the dose dependent activity of Kadukkai Choornam. Conclusion: It can be concluded that the Siddha classical preparation of Kadukkai Chooranam was effective in reducing the total cholesterol, triglycerides, $L D L, V L D L$ and increases the high density lipoprotein level successfully and proved the traditional claim of hypolipidemic activity.
\end{abstract}

Key words: cholesterol, hypolipidemic activity, Kadukkai Choornam, Terminalia chebula, Triton WR - 1339, Serum triglycerides, Siddha.

\section{Introduction}

Hyperlipidemia is a heterogeneous group of disorders characterized by an excess level of cholesterol, triglycerides, low density lipoproteins (LDL) and low level of high density lipoproteins (HDL) in the bloodstream ${ }^{[1]}$. This disorder, regardless of cause, is one of the major modifiable risk factor for coronary artery disease $(\mathrm{CAD})$ and cerebrovascular disorder (CVA) due to atherosclerosis ${ }^{[2]}$. The prevalence of hyperlipidemia is in the range of $39 \%, 51 \%$ and $26 \%$ worldwide, developed and developing countries respectively ${ }^{[3]}$.

Hyperlipidemia increases with chronological age. Women and men ratio in hyperlipidemia is 40:37 and this level increase in the risk of vascular diseases (MI / CVA) is in direct proportion. Responsibility of elevated total cholesterol and especially LDL-cholesterol is now well established in the occurrence of cardiovascular disease.

Overall, raised cholesterol is estimated to cause 2.6 million deaths (4.5\% of total) and 29.7 million disability adjusted life years (DALYS), or 2.0\% of total DALYS. 10\% reduction in serum cholesterol in men aged 40 has been reported to result in a $50 \%$ reduction in a heart disease within 5 years, the same serum cholesterol reduction for men aged 70 years can result in an average $20 \%$ reduction in heart disease occurrence in the next 5 years. ${ }^{[4]}$. A recent Meta - analysis of 38 primary and secondary prevention trials found that for every $10 \%$ reduction in serum cholesterol, mortality due to coronary heart disease was reduced by $15 \%$ and total mortality risk by $11 \% .{ }^{[5]}$

With the etiological prominence of hyperlipidemia in coronary heart disease and cerebrovascular disease various drugs have been utilized to lower the blood lipids in modern medicine and also reported side effects such as gastro intestinal disturbances, myalgia, headache and rashes reduce the compliance of the patients getting medicated with them ${ }^{[6]}$. Hence, research still continues to find out more effective and safe drug for hyperlipidemia. Natural resources provide remarkable remedy for many diseases including obesity due to hyperlipidemia without or less side effects. There are number of herbal remedies used in Siddha system of medicine to treat hyperlipidemia successfully. But there are very few studies attempted to validate the mechanism involved in the hypolipidemic action of the few plants. 
One of the trial drug Kadukkai Choornam (Terminalia chebula) has been classified under rejuvenating drug (Kayakalpa drugs) and reported as hypolipidemic agent. In Siddha system of medicine Kayakalpa drugs are considered as antioxidants which helps in reducing the LDL level and prolong the longevity of human life with free from diseases. The previous studies proved that extracts of Tripala Choornam (one of the ingredient is Terminalia chebula) has been effective against hyperlipidemia as in combinations therapy. ${ }^{[7]}$

Another study showed the lipid lowering effect of phytosterols and natural antioxidants ${ }^{[8]}$. Terminalia chebula contains high amounts of phytosterols, saponins, polyphenols, chebulinic acid and corilagen, antioxidant constituents of the plant, phloroglucinol and pyrogallol, have been isolated along with ferulic, vanillic, p-coumaric and caffeic acids which has beneficial effect in the treatment of hyperlipidemia. Based on the above facts, the present work was carried out to confirm the hypolipidemic activity in triton induced hyperlipidemic rats.

\subsection{Collection and authentication of raw drug:}

\section{Materials and Methods}

Fresh fruits of Terminalia chebula (Kadukkai) were collected during the month of June (2012) from Kollimalai, Salem Dist, Tamilnadu, India and dried well. The dried raw drug was identified and authenticated by the botanist, Siddha Central Research Institute, Chennai by correlating the macroscopic characters. The sample specimen has been kept in the department for future reference.

\subsection{Preparation of Kadukkai Chooranam}

Kadukkai Chooranam (KC) was prepared as per Standard Operating Procedure (SOP) ${ }^{[9]}$. The pericarp of Terminalia chebula fruits were collected by removing the seeds. The well dried pericarps were made into very fine powder by grinding in mortar and filtered through the mesh of the sieve size no. 125. The fine powder was subjected for purification by the Pittaviyal (steam boiling with milk) method. The powder was moistened with cow's milk. The pot was half filled with milk and water. The mouth of the pot was covered with white cotton cloth. The powder (moistened by milk) was placed above the cloth. The mouth of the pot closed tightly with another mud pot to avoid evaporation. Then, this arrangement was put on fire and boiled until water level gets reduced in the lower pot. Then, the powder was taken out, and dried, and powdered finely, and preserved in an air tight container. According to Siddha classical text, the shelf life of Kadukkai Choornam (KC) is 3 months. ${ }^{[10]}$

\subsection{Animals}

Wistar albino adult male rats weighing 150-200gm from animal housing facility of Vels University were housed in polypropylene cages maintained with temperature $27^{\circ} \mathrm{C} \pm 1^{\circ} \mathrm{C}$ and $12 \mathrm{hrs} \mathrm{light}$ and dark cycles. The animals were allowed to adapt to the environment for seven days and supplied with a standard pellet diet (Sai Durga foods, Bangalore) and water ad libitum. The experimental protocol has got the approval IAEC bearing no (XIII/ VELS/ PCOL/ 10/ 2000/ CPCSEA/ IAEC/ 08.08.2012).

\subsection{Pharmacological Evaluation}

All animals starved for 18 hours and provided water ad libitum before the experiment. The animals were divided into five groups of six rats each. Group I served as normal control administered with $2 \% \mathrm{CMC}$ only. Group II served as hyperlipidemic control given a single dose of triton was administered $400 \mathrm{mg} / \mathrm{kg}$ only. Group III and IV served as test groups received KC $250 \mathrm{mg} / \mathrm{kg}$ and $\mathrm{KC} 500 \mathrm{mg} / \mathrm{kg}$ respectively. Group V served as Lovastatin $(10 \mathrm{mg} / \mathrm{kg} / \mathrm{day})$ considered as standard. All the groups except the normal control group administered a single dose of Triton WR - 1339 dissolved in $0.9 \%$ Normal saline intraperitonially. After inducing the hyperlipidemia, the respective treatment was continued for 7 days. Animals were given standard pellet diet and water ad libitum.

\subsection{Collection of blood}

The next day after the completion of experimental study, the blood was taken from the rats under mild anesthetic state by retro orbital sinus puncture. The collected blood samples were centrifuged $(2500 \mathrm{rpm})$ for 10 minutes. Then serum samples were separated and it was used for various biochemical analyses. Then animals were sacrificed and the liver, heart and kidney were taken for histopathological study and for the analysis of organ weight.

\subsection{Liver lipid extraction}

The liver was homogenized in cold $0.15 \mathrm{M} \mathrm{KCl}$ and extracted with $\mathrm{CHCl} 3: \mathrm{CH} 3 \mathrm{OH}(2 \% v / v)$. This lipid extract was used for the estimation of lipid parameters ${ }^{[11]}$. 


\subsection{Biochemical analysis}

The serum and liver were analyzed for serum total cholesterol, triglycerides, high-density lipoprotein (HDL), low-density lipoprotein (LDL), very low-density lipoprotein (VLDL) by standard enzymatic calorimetric methods ${ }^{[12-14]}$.

\subsection{Histopathology}

All rats were sacrificed after the collection of blood sample. Liver was excised from the rats to visually detect gross lesions, and weighed to determine weight variation and preserved in $10 \%$ neutral formalin for histopathological assessment. The tissue was embedded in paraffin, and then sectioned, stained with haematoxylin and eosin and were examined microscopically.

\section{Statistical Analysis}

The obtained data statistically analyzed by one way ANOVA followed by Dunnet's multiple comparison tests. $\mathrm{p}<0.05$ considered as significant, $\mathrm{p}<0.01$ considered as highly significant and $\mathrm{p}<0.001$ considered as extremely significant.

\section{Results}

Experimental dose of Kadukkai Choornam is fixed as 250 and $500 \mathrm{mg} / \mathrm{kg}$ in evidence to the acute toxicity studies as they are safe up to that range.

In the present study, hyperlipidemia was chemically induced by Triton WR - 1339 dissolved in $0.9 \%$ normal saline (400 mg/kg body weight) at a single intraperitoneal dose. Administration of Triton WR - 1339 into rats produce hyperlipidemia by increase in the cholesterol, cholate and other lipid fractions of their blood stream. The serum lipids level was increased after 24 hours of Triton administration ${ }^{[15]}$.

\subsection{Body weight}

The effect of body weight of Triton-induced hyperlipidemic rats in all trial drug groups, standard group and control group is shown in TABLE.1. A highly significant increase in body weight was observed in the control group from the first week to the fourth week $(\mathrm{p}<0.01)$. But no marked changes in body weight were observed in trial drug treated groups and standard group.

\subsection{Serum lipid profile}

The result of lipid profile study of triton induced rats is given in TABLE.2 and Graph No.1. Total Cholesterol, triglycerides, LDL, HDL and VLDL levels were significantly increased in Triton control group compared to normal control group. There was a significant difference between the treated group when compared to the control and untreated groups. In this study, Kadukkai Chooranam dose of 250 and $500 \mathrm{mg} / \mathrm{kg}$ respectively resulted in rats rendered hyperlipidemic, a significant decrease in total cholesterol $(73.5 \pm 1.23 \mathrm{mg} / \mathrm{dl}$ and $68.33 \pm 1.45 \mathrm{mg} / \mathrm{dl})$, plasma triglycerides $(73.67 \pm 0.99 \mathrm{mg} / \mathrm{dl}$ and $56.83 \pm 0.90 \mathrm{mg} / \mathrm{dl})$, Low density lipoprotein $(72.17 \pm 1.38 \mathrm{mg} / \mathrm{dl}$ and $56.33 \pm 1.02)$ and very low density lipoprotein $(14.33 \pm 0.80 \mathrm{mg} / \mathrm{dl}$ and $11.17 \pm 1.25)$ compared to the triton treated control group and significant increase in High density lipoprotein $(39.33 \pm 0.88 \mathrm{mg} / \mathrm{dl}$ and $42.17 \pm 1.14)$ compared to the triton treated group. Treatment of KC $500 \mathrm{mg} / \mathrm{kg}$ exerted more effect than KC $250 \mathrm{mg} / \mathrm{kg}$ and also the result of $500 \mathrm{mg}$ dose $\mathrm{KC}$ was comparatively similar to that of standard group.

\subsection{Liver lipid profile}

Liver lipid profile of the present study was tabulated in TABLE No.3 and Graph No.2. Triton significantly increased TC, TG, LDL and VLDL and significantly decreased HDL concentration in triton control group. Whereas in drug treated groups (KC 250 and $\mathrm{KC} 500 \mathrm{mg}$ ) and standard group, there was statistically significant decrease in the TC, TG, LDL and VLDL and increase in the HDL concentration in rats as compared to control group.

\subsection{Atherogenic index}

Atherogenic index of triton control group and percentage protection of drug treated groups were summarized in TABLE No.4 and Graph No.3 and 4. Atherogenic index was increased significantly $(5.20 \pm 0.20)$ in triton control group as compared to the untreated group. There was no protection percentage observed in triton control group. While in drug treated groups (KC $250 \mathrm{mg}$ and $\mathrm{KC} 500 \mathrm{mg}$ ) and standard group, the index was maintained at normal value $(0.87 \pm 0.01 ; 0.62 \pm 0.02$ and $0.28 \pm 0.02)$ respectively. Percentage of protection of KC 250, KC 500 and standard group was 83,88 and 95 respectively.

Atherogenic index is closely related to the ratio between the bad cholesterol (LDL) or Total cholesterol and good cholesterol (HDL). "The zone of atherogenic risk" reflects the balance between the atherogenic and 
protective lipoproteins. Clinical studies have shown that atherogenic index predicts cardiovascular risk. It is one of the cardiovascular risk marker and a useful measure of response to treatment. Normal Atherogenic index should be below 4.5. If it is increased above this level, the atherogenic risk increases in proportion to the elevation.

\subsection{LFT, Urea and Blood glucose}

The result of other biochemical parameters like liver panel (AST, ALT and Total protein), Urea and blood glucose values are summarized in TABLE No.5 and Graph No.5. The result revealed the significant elevation of AST, ALT and Total protein and mild elevation of urea and blood glucose level in triton treated group indicating that triton induces liver damage in triton control group. However, pretreatment with KC $250 \mathrm{mg}$, KC $500 \mathrm{mg}$ and Lovastatin $10 \mathrm{mg}$ significant $(\mathrm{p}<0.01)$ decreased the serum levels of these marker enzymes, TP, Urea and maintain the blood glucose level with in the normal range in dose-dependent manner when compared with triton control group values.

\subsection{Organ weight}

Weight of liver, heart and kidney were summarized in TABLE No.6 and Graph No.6. There was no significant change in organ weight were observed in all the drug treated groups and standard groups. But the weight of all the three organs was increased significantly in triton control group.

\section{Discussion}

The reduction in cholesterol may indicate the increased oxidation of mobilized fatty acids by inhibition or lipolysis. ${ }^{[16]}$ The present investigation showed that all triton induced rats displayed hyperlipidemia as shown by their elevated levels of serum and liver cholesterol, triglyceride, VLDL, LDL and also the reduction in the HDL level. Literature reveals that an increase in HDL cholesterol and decrease in TC, LDL cholesterol and TG is associated with a decrease in the risk of ischemic heart diseases.

In general, consumption of more fat may lead to the production of increased VLDL, resulting in the formation of maximum amounts of LDL which may stick to the walls of the blood vessels causing blockages for the normal flow of blood. The strong association between the risk of coronary artery diseases (CAD), high levels of LDL-C and low levels of HDL-C has been well established ${ }^{[17,18]}$.

Triton Wr-1339 has been widely used to block the clearance of triglyceride-rich lipoproteins to induce acute hyperlipidemia ${ }^{[19]}$ particularly, in rats it has been used for screening natural or chemical hypolipidemic drugs. ${ }^{[20]}$ The results showed that Kadukkai Chooranam produced a significant reduction in cholesterol level and also it reversed Triton induced hypolipidemic in rats. Similarly, Kadukkai Chooranam at a dose of 250 and $500 \mathrm{mg} / \mathrm{kg}$ significantly lowered both plasma triglycerides and cholesterol levels. The reduction of total cholesterol by the Kadukkai Chooranam at the dose level of 250 and $500 \mathrm{mg} \mathrm{kg}$ may be associated with a decrease of LDL, which is the ultimate aim of many hypolipidemic agents.

This study suggests that cholesterol-lowering activity of the Kadukkai Chooranam may increase the fecal excretion of bile acids and neutral sterols with the consequent reduction of hepatic cholesterol because of its use in the biosynthesis of these bile acids. These fractions also slow down the rate of diffusion through the intestinal mucosa thereby reducing the absorption of cholesterol and triglycerides. Anti oxidant constituents of Kadukkai, phloroglucinol and pyrogallol also prevent the endogenous oxidation of cholesterol result in decrease in the concentration of low density lipoprotein and again confirms the hypolipidemic drug.

Table 1: Effect of Kadukkai Chooranam on body weight of Triton-induced hyperlipidemic rats

\begin{tabular}{|c|c|c|c|c|c|}
\hline \multirow{2}{*}{ Groups } & \multicolumn{5}{|c|}{ Body Weight (gm.) } \\
\cline { 2 - 6 } & Initial & $\mathbf{1}^{\text {st }}$ Week & $\mathbf{2}^{\text {nd }}$ Week & $\mathbf{3}^{\text {rd }}$ Week & $\mathbf{4}^{\text {th }}$ Week \\
\hline Normal control & $154 \pm 0.97$ & $156 \pm 1.39$ & $158.25 \pm 1.03^{* *}$ & $160.5 \pm 2.72^{* *}$ & $163.6 \pm 3.17^{* *}$ \\
\hline $\begin{array}{c}\text { Hyperlipidemic } \\
\text { Control }\end{array}$ & $156.17 \pm 0.87$ & $157 \pm 1.03$ & $178.17 \pm 1.17$ & $196.5 \pm 0.76$ & $236 \pm 1.09$ \\
\hline KC 250mg/kg & $153.83 \pm 0.79$ & $157 \pm 0.97$ & $166.75 \pm 1.47^{*}$ & $168.42 \pm 1.23^{* *}$ & $170.83 \pm 2.30^{* *}$ \\
\hline KC 500mg/kg & $156.5 \pm 0.67$ & $158.5 \pm 1.89$ & $166.33 \pm 0.80^{*}$ & $166.67 \pm 0.76^{* *}$ & $169.83 \pm 0.87^{* *}$ \\
\hline $\begin{array}{c}\text { Lovastatin } \\
(\mathbf{1 0 m g} / \mathbf{k g} / \mathbf{d a y})\end{array}$ & $155 \pm 1.59$ & $158.17 \pm 1.08$ & $165.5 \pm 1.18^{* *}$ & $164.17 \pm 0.91^{* *}$ & $166.5 \pm 0.89^{* * *}$ \\
\hline
\end{tabular}


Hypolipidemic activity of Kadukkai Chooranam (Terminalia chebula) in Triton WR - 1339 induced

Values are as mean \pm SEM $(n=6)$. Values are statistically significant at $* P<0.05, * * P<0.01$, ***P<0.001. Comparison made between Group II Vs Group I and Group III, IV, V Vs Group II.

Table 2: Effect of Kadukkai Chooranam on Blood lipid profile of Triton-induced hyperlipidemic rats.

\begin{tabular}{|c|c|c|c|c|c|c|}
\hline $\begin{array}{l}\text { Gro } \\
\text { up }\end{array}$ & Treatment & T.C. & T.G. & LDL & HDL & VLDL \\
\hline I & $\begin{array}{c}\text { Normal } \\
\text { Control }\end{array}$ & $70.83 \pm 1.19^{* *}$ & $66.17 \pm 1.47^{* *}$ & $50.83 \pm 1.28^{* *}$ & $35.33 \pm 1.43$ & $18.33 \pm 1.02^{* *}$ \\
\hline II & $\begin{array}{c}\text { Triton } \\
\text { Control }\end{array}$ & $174.17 \pm 1.35$ & $125.17 \pm 1.49$ & $122.17 \pm 1.25$ & $28.17 \pm 1.08$ & $25.83 \pm 1.51$ \\
\hline III & KC 250mg/kg & $73.5 \pm 1.23^{* *}$ & $73.67 \pm 0.99^{* *}$ & $72.17 \pm 1.38^{* *}$ & $39.33 \pm 0.88^{*}$ & $14.33 \pm 0.80^{* *}$ \\
\hline IV & KC 500mg/kg & $68.33 \pm 1.45^{* *}$ & $56.83 \pm 0.90^{* *}$ & $56.33 \pm 1.02^{* *}$ & $42.17 \pm 1.14^{* *}$ & $11.17 \pm 1.25^{* *}$ \\
\hline V & Lovastatin & $55.5 \pm 1.12^{* *}$ & $55.83 \pm 1.30^{* *}$ & $45.33 \pm 1.15^{* *}$ & $43.33 \pm 1.36^{* *}$ & $10.5 \pm 1.87^{* *}$ \\
\hline
\end{tabular}

Values are as mean \pm SEM $(n=6)$. Values are statistically significant at $* P<0.05, * * P<0.01, * * * P<0.001$. Comparison made between Group II Vs Group I and Group III, IV, V Vs Group II.

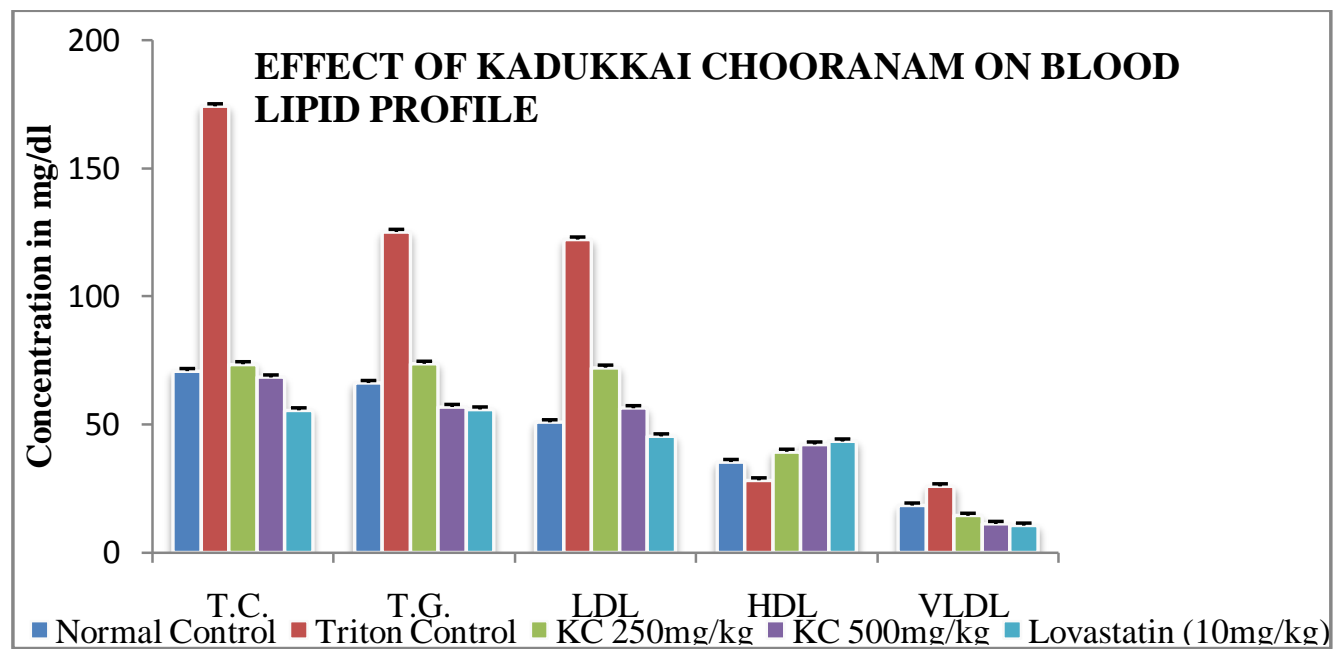

Graph.1.Effect of Kadukkai Chooranam on blood lipid profile

Table 3: Effect of Kadukkai Chooranam on liver lipid profile of Triton-induced hyperlipidemic rats.

\begin{tabular}{|c|c|c|c|c|c|c|}
\hline Group & Treatment & T.C. & T.G. & LDL & HDL & VLDL \\
\hline I & $\begin{array}{c}\text { Normal } \\
\text { Control }\end{array}$ & $74.17 \pm 0.87^{* *}$ & $70.75 \pm 1.93^{* *}$ & $26.17 \pm 1.70^{* *}$ & $36.17 \pm 0.91$ & $13.58 \pm 1.24^{* *}$ \\
\hline II & Triton Control & $155.17 \pm 1.08$ & $178.82 \pm 1.46$ & $105.25 \pm 2.42$ & $18.15 \pm 1.05$ & $35.1 \pm 0.93$ \\
\hline III & KC 250mg/kg & $82.15 \pm 0.92^{* *}$ & $64.15 \pm 1.03^{* *}$ & $23.12 \pm 1.01^{* *}$ & $35.9 \pm 0.86$ & $12.22 \pm 0.25^{* *}$ \\
\hline IV & KC 500mg/kg & $75.3 \pm 0.85^{* *}$ & $64.12 \pm 0.97^{* *}$ & $20.3 \pm 1.06^{* *}$ & $44.05 \pm 1.40^{*}$ & $12.88 \pm 1.12^{* *}$ \\
\hline V & $\begin{array}{c}\text { Lovastatin } \\
(\mathbf{1 0 m g / k g / d a y )}\end{array}$ & $67.05 \pm 0.97^{* *}$ & $57.25 \pm 1.15^{* *}$ & $17.93 \pm 1.31^{* *}$ & $50.1 \pm 0.99^{*}$ & $12.1 \pm 0.91^{* *}$ \\
\hline
\end{tabular}

Values are as mean \pm SEM $(n=6)$. Values are statistically significant at $* P<0.05, * * P<0.01$, ***P<0.001. Comparison made between Group II Vs Group I and Group III, IV, V Vs Group II. 


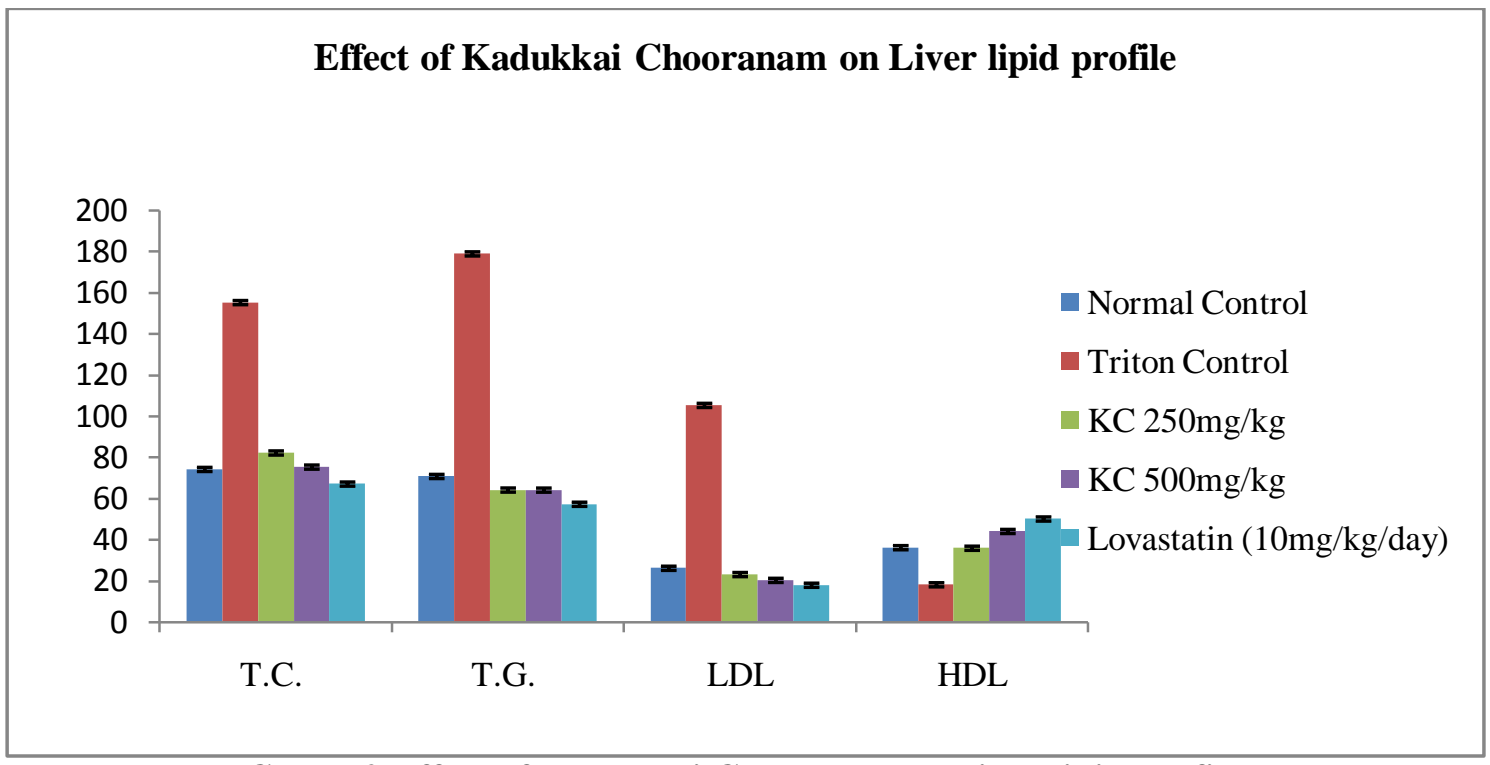

Graph.2.Effect of Kadukkai Chooranam on liver lipid profile

Table 4: Effect of Kadukkai Chooranam on atherogenic index and percentage protection of different groups.

\begin{tabular}{|c|c|c|}
\hline Groups & Atherogenic Index & \% Protection \\
\hline Normal control & $1.01 \pm 0.05$ & -- \\
\hline Hyperlipidemic Control & $5.20 \pm 0.20$ & -- \\
\hline KC 250mg/kg & $0.87 \pm 0.01$ & 83 \\
\hline KC 500mg/kg & $0.62 \pm 0.02$ & 98 \\
\hline Lovastatin & $0.28 \pm 0.02$ & 95 \\
\hline
\end{tabular}

Values are as mean \pm SEM (n=6). Values are statistically significant at $* P<0.05, * * P<0.01$, ***P<0.001. Comparison made between Group II Vs Group I and Group III, IV, V Vs Group II.
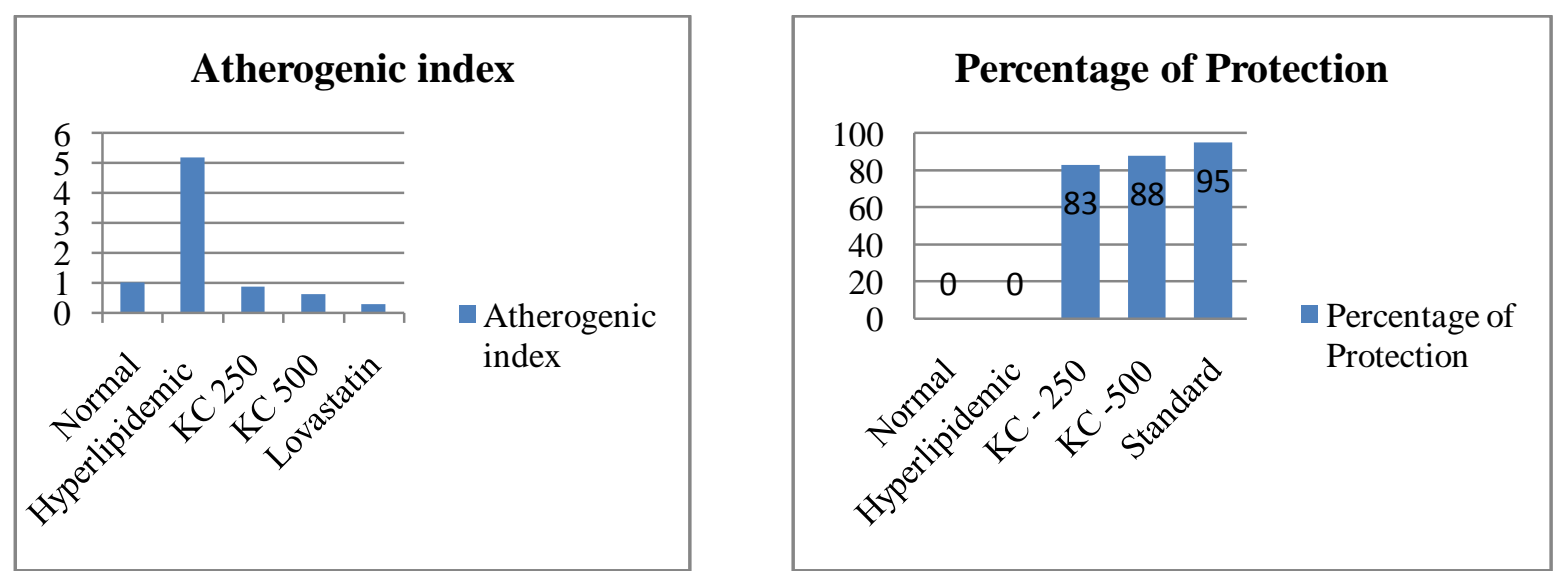

Graph.3 and 4. Showing \% of Atherogenic index and \% of protection of drug treated rats. 
Table 5: Effect of Kadukkai Chooranam on SGOT, SGPT Total protein, Urea and Blood glucose levels of Triton-induced hyperlipidemic rats

\begin{tabular}{|c|c|c|c|c|c|}
\hline Groups & SGOT(U/I) & SGPT(U/I) & $\begin{array}{c}\text { Total } \\
\text { Protein } \\
\text { (gm/dl) }\end{array}$ & $\begin{array}{c}\text { Urea } \\
(\mathbf{m g} / \mathbf{d l})\end{array}$ & $\begin{array}{c}\text { Blood Glucose } \\
(\mathbf{m g} / \mathbf{d l})\end{array}$ \\
\hline Normal control & $168.17 \pm 1.08$ & $61.17 \pm 0.87$ & $6 \pm 0.86^{*}$ & $26 \pm 0.97$ & $84.83 \pm 0.79$ \\
\hline $\begin{array}{c}\text { Hyperlipidemic } \\
\text { Control }\end{array}$ & $230.33 \pm 1.12$ & $130.5 \pm 0.76$ & $7.0 \pm 0.97$ & $42 \pm 1.18$ & $93.14 \pm 0.74$ \\
\hline KC 250mg/kg & $176.5 \pm 1.67$ & $81 \pm 2.03$ & $6.68 \pm 1.08^{*}$ & $34.02 \pm 1.31$ & $84.83 \pm 1.08$ \\
\hline KC 500mg/kg & $160 \pm 1.18^{* *}$ & $72.37 \pm 0.89^{* *}$ & $6.17 \pm 1.02$ & $26.6 \pm 1.27^{* *}$ & $83.08 \pm 1.30^{* *}$ \\
\hline $\begin{array}{c}\text { Lovastatin } \\
(\mathbf{1 0 m g / k g / d a y )}\end{array}$ & $157.52 \pm 1.74$ & $64.05 \pm 1.35$ & $6.03 \pm 0.90$ & $26.67 \pm 0.76$ & $82.17 \pm 0.87$ \\
\hline
\end{tabular}

Values are as mean $\pm S E M(n=6)$. Values are statistically significant at $* P<0.05, * * P<0.01$, ***P<0.001. Comparison made between Group II Vs Group I and Group III, IV, V Vs Group II.

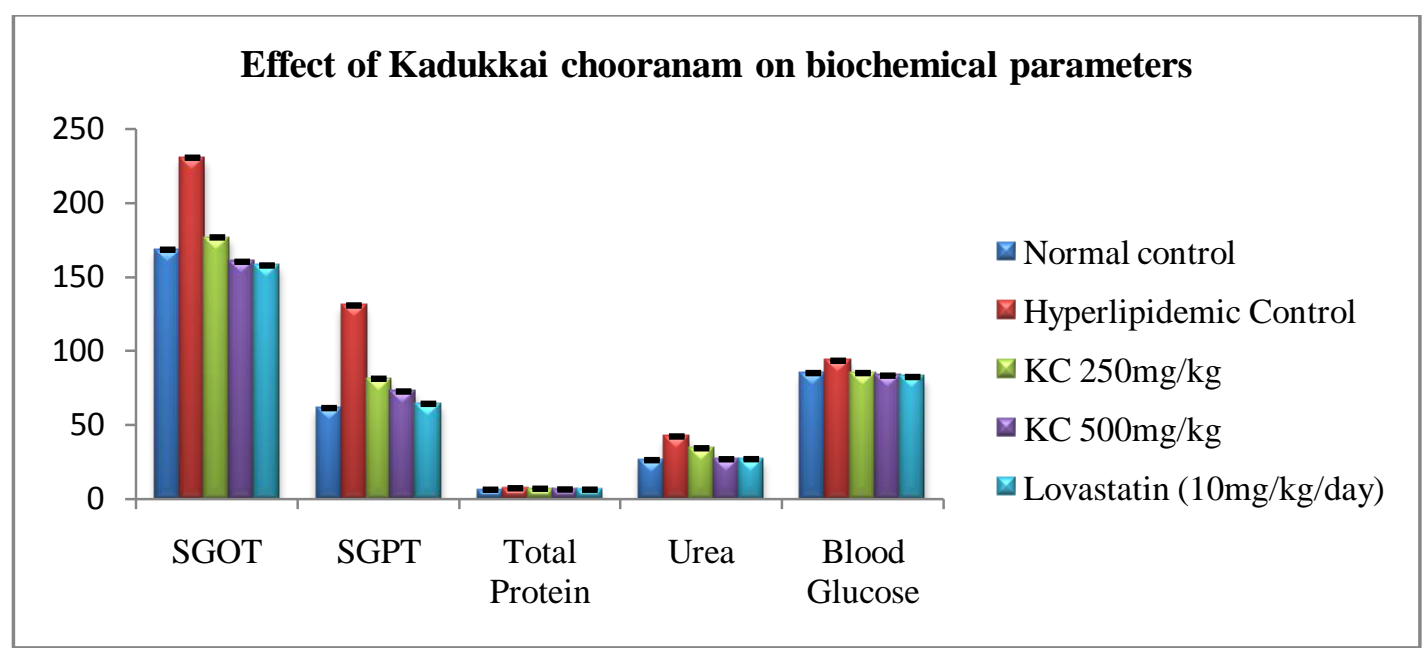

Graph.5. Effect of Kadukkai Chooranam on biochemical parameters.

Table 6: Effect of Kadukkai Chooranam on vital organ weights of Triton-induced hyperlipidemic rats on day 24.

\begin{tabular}{|c|c|c|c|}
\hline Groups & Liver(gm) & Heart(gm) & Kidney(gm) \\
\hline Normal control & $5.5 \pm 0.40^{* *}$ & $0.6 \pm 0.10^{* *}$ & $0.52 \pm 0.13$ \\
\hline $\begin{array}{c}\text { Hyperlipidemic } \\
\text { Control }\end{array}$ & $7.35 \pm 0.45$ & $1.15 \pm 0.14$ & $0.8 \pm 0.05$ \\
\hline KC 250mg/kg & $6.18 \pm 0.96^{* *}$ & $0.62 \pm 0.07 * *$ & $0.6 \pm 0.10$ \\
\hline KC 500mg/kg & $5.87 \pm 0.73^{* *}$ & $0.62 \pm 0.10^{* *}$ & $0.60 \pm 0.10$ \\
\hline $\begin{array}{c}\text { Lovastatin } \\
(\mathbf{1 0 m g / k g / d a y )}\end{array}$ & $5.18 \pm 1.00^{* *}$ & $0.61 \pm 0.10^{* *}$ & $0.60 \pm 0.06$ \\
\hline
\end{tabular}

Values are as mean \pm SEM (n=6). Values are statistically significant at $* P<0.05, * * P<0.01$, ***P<0.001. Comparison made between Group II Vs Group I and Group III, IV, V Vs Group II. 


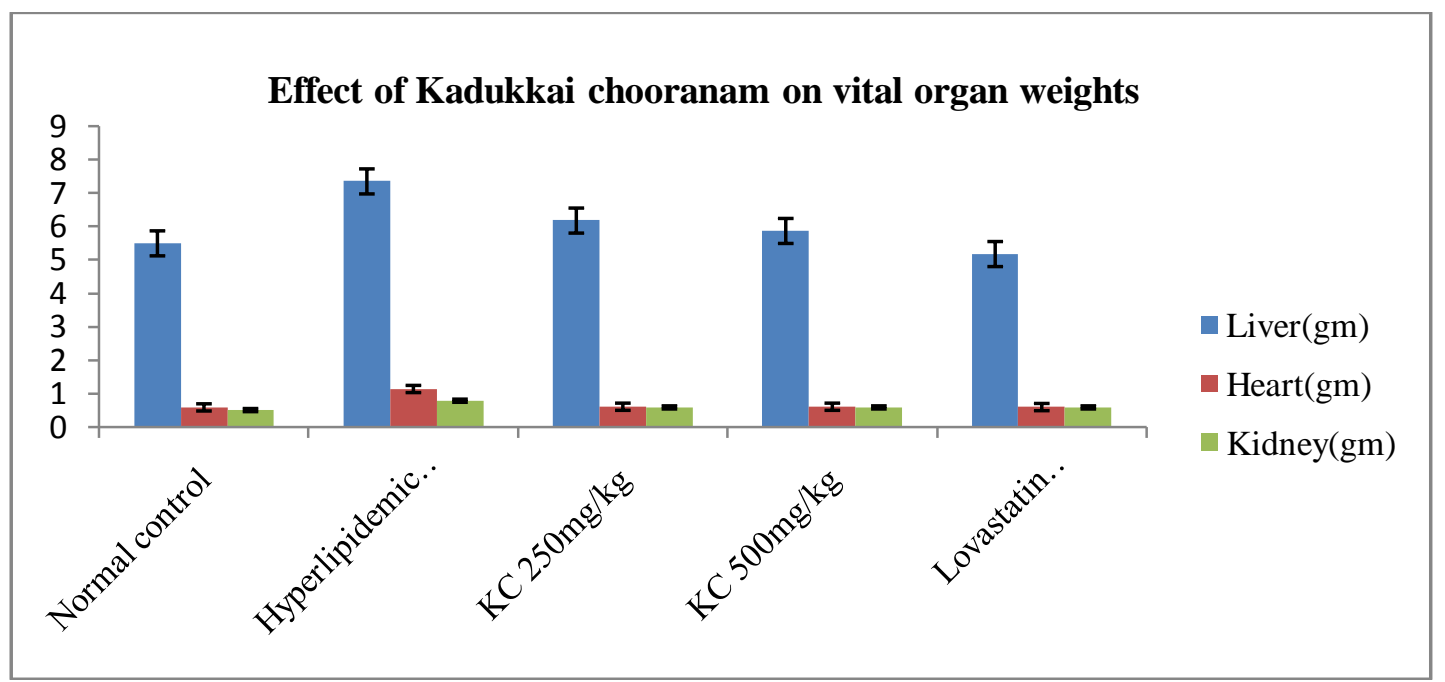

Graph.6. Effect of Kadukkai Chooranam on vital organ weights

\section{Conclusion}

Therefore, it can be concluded that Kadukkai Chooranam 250 and $500 \mathrm{mg}$ treatment was effective in cholesterol, TG, VLDL, LDL and HDL. The hypolipidemic activity of Kadukkai Chooranam against Triton Wr1339 showed dose dependent activity when compared to control as well as Lovastatin treated groups. The understanding of the mechanism involved in the activity of Kadukkai Chooranam for its hypolipidemic activity mainly due to the presence of anti oxidant compounds phloroglucinol and pyrogallol which synergistically working together to modify the lipid profile. Hence, the present study proved the traditional claim of hypolipidemic activity of Kadukkai Choornam.

\section{Acknowledgement}

We would like to express our sincere thanks to the Principal and HOD, Government Siddha Medical College, Arumbakkam, Chennai and Department of Pharmacology, School of Pharmaceutical Sciences, Vel's University, Chennai for their valuable advice and guidance throughout this study.

\section{References}

[1] Davidson's Principles and practice of Medicine. $21^{\text {st }}$ edition page no.451

[2] KD.Tripathi; Medical pharmacology-sixth edition-2010 page no.619

[3] Hyperlipidemia epidemiology and demographics. Wiki doc Editor-In-Chief: C. Michael Gibson, Hardik Patel ib.wikidoc.org/index.php/Hyperlipidemia_epidemiology_and_demographics (2013).

[4] World Health Organization, Global Health Observatory (GHO); Raised cholesterol; Situation and trends; Risk factors; Geneva: 2013

[5] Gould, AL, Rossouw, JE, Santanello, NC, et al. Cholesterol reduction yields clinical benefit: Impact of statin trials. Circulation 1998; 97:946.

[6] KD.Tripathi; Medical pharmacology-sixth edition-2010 page no.615

[7] Selvaraj Saravanan et al,Aug 2006Hypolipidemic effect of Triphala in experimentally induced hypercholesteraemic rats

[8] Visavadiya NP, R.L. Narasimhacharya Hypolipidemic and antioxidant activities of Asparagus racemosus in hypercholesteraemic rats AV Indian Journal of Pharmacology, Vol. 37, No. 6, November-December, 2005, pp. 376-380

[9] Murugesa Mudhaliar Gunapadam 2008) page no. 207

[10] R.Thiyaga Rajan Gunapadam-Thathu Jeeva vaguppu 2009) Page no.61,56

[11] LDing ZY, Chen Y, Zhou M and Fang YZ. Inhibitory effect of green tea polyphenol and murin on the oxidative modification of lowdensity lipoprotein. Clin. J. Pharmacol. Toxicol, 6, 1992, 263-266.

[12] Allain CC, Poon LS, Chan CS, Richmond WF, Determination of total cholesterol in serum, Pubmed, 1974 Apr;20(4): 470-5

[13] Paul S, Bachorik, Robert Walker, Kelly D.Brownell, Albert J.Stunkard and Peter O.Kwiterovich, Determination of high density lipoprotein - cholesterol in stored human plasma: Journal of Lipid Research, July 1980, Vol.21, 608-616.

[14] Giovanni Bucolo and Harold David, Quantitative determination of serum triglycerides by the use of enzymes: The American Association for clinical chemistry, 1973, Vol.19, 476-482.

[15] Vogel WH, Scholkens BA, Sandow J, Muller G, Drug discovery and evaluation, 2nd ed. New York: Springer- Verlog Berlin Hiedelberg, 2002, 1103-1104

[16] Pourush Badal, Rajendra Mani Badal. Hypolipidemic activity of Perosolinum cripsum plant in Triton WR-1339 induced rats. Herbal Tech Industry p.89

[17] Castelli WP. Cholesterol and lipids in the risk of coronary artery disease-the Framingham Heart study. Can J Cardiol. 1988; 4:5-10.

[18] Igweh JC, Nwagha IU, Okaro JM. The Effects of Menopause on the Serum lipid profile of Normal Females of South East Nigeria. Nigerian Journal of Physiological Sciences. 2005; 20(1-2):48-53.

[19] A.Kellner, J.W.Correll and A.T.Ladd. Sustained hyperlipidemia induced in rabbits by means of intravenously injected surface active agents. J.of.Exp.Medicine. 93:373-384(1951).

[20] P.E.Schurr, J.R.Schultz and T.M.Parkinson. Triton induced hyperlipidemia in rats as an animal model for screening hypolipidemic drugs. Lipids. 7:69-74(1972). 